\title{
Terrestrial laser scanning intensity captures diurnal variation in leaf water potential
}

\author{
S. Junttila ${ }^{\text {a,b, }}$, T. Hölttä ${ }^{b}$, E. Puttonen ${ }^{c}$, M. Katoh ${ }^{\text {d }}$, M. Vastaranta ${ }^{\text {a }}$, H. Kaartinen ${ }^{\text {c,e }}$, \\ M. Holopainen ${ }^{\mathrm{b}}$, H. Hyyppä ${ }^{\mathrm{f}}$ \\ ${ }^{a}$ School of Forest Sciences, University of Eastern Finland, Joensuu 80101, Finland \\ ${ }^{\mathrm{b}}$ Department of Forest Sciences, University of Helsinki, Helsinki 00014, Finland \\ ${ }^{\mathrm{c}}$ Department of Remote Sensing and Photogrammetry, Finnish Geospatial Research Institute, National Land Survey of Finland (NLS), Masala 02431, Finland \\ ${ }^{\mathrm{d}}$ Institute of Mountain Science, Shinshu University, 8304, Minamiminowa-Village, Kamiina-County, Nagano 399-4598, Japan \\ e Department of Geography and Geology, University of Turku, 20500 Turku, Finland \\ ${ }^{\mathrm{f}}$ Department of Built Environment, School of Engineering, Aalto University, 02150 Espoo, Finland
}

\section{A R T I C L E I N F O}

\section{Keywords:}

Leaf water potential

Lidar intensity

Terrestrial laser scanning

Diurnal variation

Leaf water content

Drought

Tree health

Plant water dynamics

\begin{abstract}
A B S T R A C T
During the past decades, extreme events have become more prevalent and last longer, and as a result droughtinduced plant mortality has increased globally. Timely information on plant water dynamics is essential for understanding and anticipating drought-induced plant mortality. Leaf water potential $\left(\Psi_{\mathrm{L}}\right)$, which is usually measured destructively, is the most common metric that has been used for decades for measuring water stress. Remote sensing methods have been developed to obtain information on water dynamics from trees and forested landscapes. However, the spatial and temporal resolutions of the existing methods have limited our understanding of the water dynamics and diurnal variation of $\Psi_{\mathrm{L}}$ within single trees. Thus, we investigated the capability of terrestrial laser scanning (TLS) intensity in observing diurnal variation in $\Psi_{\mathrm{L}}$ during a 50 -h monitoring period. We aimed to improve the understanding on how large a part of the diurnal variation in $\Psi_{\mathrm{L}}$ can be captured using TLS intensity observations. We found that TLS intensity at the $905 \mathrm{~nm}$ wavelength measured from a static position was able to explain $77 \%$ of the variation in $\Psi_{\mathrm{L}}$ for three trees of two tree species with a root mean square error of $0.141 \mathrm{MPa}$. Based on our experiment with three trees, a time series of TLS intensity measurements can be used in detecting changes in $\Psi_{\mathrm{L}}$, and thus it is worthwhile to expand the investigations to cover a wider range of tree species and forests and further increase our understanding of plant water dynamics at wider spatial and temporal scales.
\end{abstract}

\section{Introduction}

Global warming is altering global hydrological cycles, which results in intensified and prolonged droughts causing forest mortality (McDowell and Allen, 2015; Trenberth, 2011). In addition to dry areas becoming dryer, more intense precipitation events occur due to the increased water holding capacity of the warmer air. Altered precipitation patterns and increased evaporation lead to increased drought frequency and severity (Dai, 2013). Water availability has been identified as one of the most significant factors determining the global sensitivity of vegetation productivity to climate variability (Seddon et al., 2016). Major shifts in vegetation patterns may therefore be expected during the following decades, affecting food security and terrestrial carbon uptake
(Beer et al., 2010; Wheeler and von Braun, 2013). Understanding the effects of altered water availability requires accurate modelling of plant hydraulics at several scales. The development of such models requires rigorous parameterization and careful testing against observations; multi-scale observations of plant water relations are therefore urgently needed (Konings et al., 2019). A wider availability of plant water measurements would also improve our ability to understand and anticipate drought-induced mortality in plants (Martinez-Vilalta et al., 2019).

Various methods based on remote sensing or in-situ measurements can be used to measure plant and leaf water status. In-situ measurements are either destructive, such as leaf sampling to measure leaf water content or leaf water potential $\left(\Psi_{\mathrm{L}}\right)$, or indirect such as the measurement of subtle changes in xylem or stem diameter with linear transducers (De

\footnotetext{
* Corresponding author at: Department of Forest Sciences, University of Eastern Finland, Yliopistokatu 7, Joensuu 80101, Finland.

E-mail address: samuli.junttila@uef.fi (S. Junttila).
} 
Swaef et al., 2015) that have been shown to correlate with $\Psi_{\mathrm{L}}$ (Cochard et al., 2002; Dietrich et al., 2018). Stem or leaf water potential can also be measured non-destructively using psychrometers, which utilize a pair of thermocouples to generate wet bulb depression (Guo et al., 2020; Savage et al., 1983). Leaf water potential is one of the most common metrics used in plant physiology and ecology to measure plant water status, as it describes the sensitivity of plant metabolic and transport processes to decreasing soil water availability and atmospheric evaporative demand. It is still mostly measured manually using a Scholander pressure chamber (Scholander et al., 1965), which is laborious to use, requires access to the canopy, and provides only a single reading of the canopy water status in time and space. Also, $\Psi_{\mathrm{L}}$ heterogeneity within the tree canopy due to variation in illumination may decrease measurement accuracy. To further understand the movement of water within the soilplant-atmosphere continuum and how the water relations of trees and forests are affected by environmental conditions, non-destructive and reproducible measurement methods capable of providing extensive spatiotemporal information on $\Psi_{\mathrm{L}}$ are urgently needed. Measuring the variation in stem or xylem diameter may provide an assessment of the plant water content and $\Psi_{\mathrm{L}}$ of trees (Dietrich et al., 2018) but cannot capture variation in leaf water content within tree canopies and demands a great deal of infrastructure for measuring many trees simultaneously.

Remote sensing methods can be used to estimate leaf water content, from which $\Psi_{\mathrm{L}}$ is estimable, as these two are closely related (Cohen et al., 2005; Cotrozzi et al., 2017; Penuelas et al., 1997). Leaf water potential can be divided into three components according to Eq. (1), where $\Psi_{\pi}$ is the osmotic potential (affected by sugars and other dissolved solutes), $\Psi_{\mathrm{P}}$ is the pressure potential that is tightly linked to relative water content, and $\Psi_{\mathrm{g}}$ is the gravitational potential that affects tall trees $(>30 \mathrm{~m})$ in particular. Osmotic potential changes at shorter time intervals due to changes in solute and water content and at longer time intervals due to drought or cold acclimation driven by active osmoregulation. Gravitational potential is constant at a given location in a tree canopy, and thus $\Psi_{\mathrm{L}}$ is mainly controlled by changes in the relative water content of leaves at short time intervals such as days (Kubiske and Abrams, 1991; Olsson and Milthorpe, 1983). Thus, measuring the change in leaf water content may be used as a proxy for estimating $\Psi_{\mathrm{L}}$.

$\Psi_{\mathrm{L}}=\Psi_{\pi}+\Psi_{\mathrm{P}}+\Psi_{\mathrm{g}}$

Leaf water potential varies during the course of a day and also seasonally. When day temperatures are high during summer, $\Psi_{\mathrm{L}}$ may vary from near 0 before sunrise to $\sim-3 \mathrm{MPa}$ at midday when water availability in the soil is not limited (Klepper, 1968; Syvertsen and Levy, 1982). Leaf water potential has also shown vertical variation, for example for peach trees (Prunus sp.) with heights of less than $5 \mathrm{~m}$ (Olsson and Milthorpe, 1983) and Norway spruce (Picea abies (L.) H. Karst.) trees less than $10 \mathrm{~m}$ in height (Hellkvist et al., 1974). Lower water potentials were detected higher in the canopy, likely due to the increased transpiration and longer transport distance to the upper parts of the crown (Olsson and Milthorpe, 1983).

Passive remote sensing has been used to measure the variation in leaf water content of individual leaves at close range and of canopies using airborne sensors (Colombo et al., 2008; Danson et al., 1992; Penuelas et al., 1997). The estimation of leaf water content using spectral information is often based on the sensitivity of the shortwave infrared (SWIR) region (1200-2200 $\mathrm{nm}$ ) to leaf water content (Ceccato et al., 2001). The near-infrared (NIR) region (700-1000 nm) is also sensitive to leaf water content (Penuelas et al., 1997). These methods are, however, dependent on solar illumination and therefore cannot be used at very low sun angles or during night-time to capture the entire diurnal cycle of plant water dynamics. These methods additionally lack the capability to measure the within-tree variation of leaf water content.

The estimation of $\Psi_{\mathrm{L}}$ has been studied using leaf spectroscopy during the last decade, but mainly focusing on grapevines (Vitis vinifera L.) (Bei et al., 2011; Rallo et al., 2014; Santos and Kaye, 2009). Cotrozzi et al.
(2017) studied the estimation of predawn $\Psi_{\mathrm{L}}$ using spectroscopic measurements from oak tree leaves (Quercus oleoides Schltdl. \& Cham.) and detected drought-induced changes in predawn $\Psi_{\mathrm{L}}$. They found that the most significant spectral features for estimating predawn $\Psi_{\mathrm{L}}$ were in the $1400-1470 \mathrm{~nm}, 1655-1675 \mathrm{~nm}, 1840-1950 \mathrm{~nm}$, and $2125-2400 \mathrm{~nm}$ regions. Rallo et al. (2014) found that vegetation indices combining bands in the NIR (710-760 nm) and SWIR (1550-1650 nm) regions provided the most accurate estimates of $\Psi_{\mathrm{L}}$. However, such methods are based on single-leaf measurements, which presents a serious issue, since they are prone to error due to the low number of samples and require access to the canopy. Other remote sensing methods used to estimate $\Psi_{\mathrm{L}}$ include thermal remote sensing (Baluja et al., 2012). Cohen et al. (2005) used a thermal camera to assess the $\Psi_{\mathrm{L}}$ of cotton plants (Gossypium arboreum L.) and found a strong correlation (coefficient of determination $\left(R^{2}\right)=0.79$ ) between leaf temperature and $\Psi_{\mathrm{L}}$ using a wet reference target. Leaf temperature increased with decreasing $\Psi_{\mathrm{L}}$. However, methods based on thermal imaging are dependent on sunlight and are thus unsuitable for capturing diurnal variation in $\Psi_{\mathrm{L}}$.

Terrestrial laser scanning (TLS), is a measurement method that can accurately capture the three-dimensional (3D) structure of trees (Dassot et al., 2011; Krooks et al., 2014). A single TLS scan, which typically takes 3-10 min, produces a point cloud of the surroundings ranging from a few metres to tens of metres. It is repeatable and allows the measurement of multiple tree canopies in high detail. TLS has been widely used to estimate various variables in forests, e.g. forest structural attributes, leaf area index, wood quality, and biomass and to quantify dead wood pools (Antonarakis et al., 2010; Kankare et al., 2013; Liang et al., 2014; Pyörälä et al., 2018; Yrttimaa et al., 2019).

In addition to the 3D structure, TLS measures the strength of the backscattered light at the used wavelength, which in the literature is commonly referred to as intensity (Kaasalainen et al., 2011). Intensity data from TLS may provide additional information on target properties due to its relationship with reflectance at the narrow band of the laser light (Kaasalainen et al., 2009). Terrestrial laser scanning utilizes an active and controlled source of light that is independent of external illumination, reducing the factors that affect the measured spectra and allowing for measurements at any time of day. Dual-wavelength TLS (DW-TLS) and hyperspectral TLS instruments can measure multiple wavelengths, enabling the calculation of spectral ratios similar to passive multispectral imaging. Spectral ratios of TLS intensity can help reduce the leaf structural and incidence angle effects on the measured reflectance (Junttila et al., 2019; Junttila et al., 2016; Nevalainen et al., 2014).

A single intensity measurement consists of the backscattered light under the footprint of the laser, which typically varies around 4-10 mm in a forest environment depending on the distance of the target. Terrestrial laser scanning intensity measurements are complicated by target geometry, which influences the intensity-distance relationship. Terrestrial laser scanning intensity can be described using the radar equation, which states that transmitted power $\left(P_{t}\right)$, aperture area $(D)$, optical efficiency $(Q)$, laser-beam divergence $(\beta)$, atmospheric transmission losses $(T)$, range $(R)$, and backscattering target cross-section $(\sigma)$ all affect the received power $\left(P_{r}\right)$ :

$P_{r}=\frac{P_{t} D Q}{4 \pi \beta^{2}} T^{2} \frac{\sigma}{R^{4}}$

where $\sigma$ comprises target reflectance, geometry, and illuminated area. The power of $R$ is, however, influenced by target size. Planar targets that cover the entire laser footprint cause a stronger backscatter, which diminishes less with distance than linear or blob-like targets due to spherical losses (Wagner et al., 2006). This is an issue with coniferous species, as the needles do not cover even the small footprint of TLS, causing complications in the distance calibration of intensity data (Junttila et al., 2019; Korpela, 2017). Generally, deciduous species do not suffer from the same problem, because leaves fill the laser footprint, 
but on the other hand incidence angle effect complicates the interpretation of TLS intensity measurements.

A clear linkage between leaf water content, measured as equivalent water thickness (EWT), and TLS intensity has been shown in several studies (Elsherif et al., 2019a; Gaulton et al., 2013; Junttila et al., 2018; Junttila et al., 2016). Reflectance at the $1550 \mathrm{~nm}$ wavelength, which is often utilized in TLS sensors, increases as the leaf water content decreases (Junttila et al., 2016; Rallo et al., 2014). Another wavelength, such as $808 \mathrm{~nm}$ or $905 \mathrm{~nm}$, is often employed for accounting leaf structural effects on the measured intensity at $1550 \mathrm{~nm}$, as they are assumed to be less sensitive to leaf water content (Elsherif et al., 2018; Junttila et al., 2018). A nearly linear relationship was found between EWT and a normalized difference index (NDI) calculated from TLS intensity at the $1550 \mathrm{~nm}$ and $690 \mathrm{~nm}$ wavelengths in a drying experiment in a laboratory environment with five species (Junttila et al., 2016). A combination of the $905 \mathrm{~nm}$ and $1550 \mathrm{~nm}$ wavelengths showed better accuracy than the $690 \mathrm{~nm}$ and $1550 \mathrm{~nm}$ wavelengths at predicting EWT in a greenhouse experiment with Norway spruce seedlings (Junttila et al., 2018). Field experiments with DW-TLS have shown promising results for estimating EWT in deciduous species but also low prediction accuracy for coniferous species due to complications arising from distance calibration issues explained above (Elsherif et al., 2019b; Junttila et al., 2019). Elsherif et al. (2019a) investigated the detection of changes in EWT during and after an intense drought event using two observation points in time and DW-TLS data at the $808 \mathrm{~nm}$ and $1550 \mathrm{~nm}$ wavelengths. However, there is still limited understanding on the capability of TLS intensity in characterizing short-term changes in leaf water content that are related to the diurnal cycle of $\Psi_{\mathrm{L}}$. Research on monitoring leaf water content changes using TLS has been limited to date.

To increase our understanding of water dynamics and the diurnal variation of $\Psi_{\mathrm{L}}$ within single trees and to overcome the temporal and spatial limitations of passive remote sensing methods and issues arising from the TLS intensity distance calibration of coniferous species, we collected a time series of 15 TLS scans at the $905 \mathrm{~nm}$ and $1550 \mathrm{~nm}$ wavelengths in the field. We studied and scanned three trees of two species with a nearly constant measurement geometry to determine the diurnal variation of $\Psi_{\mathrm{L}}$ during a 50 -h time period coupled with destructive leaf measurements and radial stem diameter measurements. As we cannot measure pressure directly, $\Psi_{\mathrm{L}}$ estimation is based on the well-established theory that a change in leaf water content is the main driver of change in $\Psi_{\mathrm{L}}$ during short time intervals such as days. Our main research question was to investigate how large a part of the diurnal variation in $\Psi_{\mathrm{L}}$ may be captured using TLS intensity observations based on the known correlation between leaf water content, $\Psi_{\mathrm{L}}$, and TLS intensity at the $905 \mathrm{~nm}$ and $1550 \mathrm{~nm}$ wavelengths. Based on existing knowledge, we hypothesized that a correlation exists between the measured intensity and $\Psi_{\mathrm{L}}$. This research contributes to increasing the understanding of tree water dynamics and to the development of novel methods to measure and monitor it.

\section{Material and methods}

We measured two Scots pines (Pinus sylvestris L.) and one silver birch (Betula pendula Roth) (Table 1) during a 50-h monitoring period from the 29th to the 31st of July 2019 at the Station for Measuring EcosystemAtmosphere Relations (SMEAR II) at Hyytiälä Forest Research Station in Juupajoki, Finland $\left(61^{\circ} 46^{\prime} \mathrm{N}, 24^{\circ} 17^{\prime} \mathrm{E}, 170 \mathrm{~m}\right.$ a.s.l.) (Table 1). The investigated trees were growing in a 57-year-old Scots pine stand with combinations of silver birch, Norway spruce (Picea abies (L.) Karst.),

Table 1

Diameters at breast height (DBH) and heights of the investigated trees.

\begin{tabular}{llll}
\hline & Scots pine 1 & Scots pine 2 & Silver birch \\
\hline DBH $(\mathrm{cm})$ & 22.5 & 19.8 & 20.1 \\
Height $(\mathrm{m})$ & 18.9 & 19.5 & 20.6 \\
\hline
\end{tabular}

rowan (Sorbus aucuparia L.), European aspen (Populus tremula L.), and common juniper (Juniperus communis L.). The trees were located around a multi-storey measurement tower enabling the collection of observations from the tree crowns during the investigation period.

Radial stem variation of the trees was measured with point dendrometers, i.e. linear variable displacement transducers (model AX/5.0/ $\mathrm{S}$, Solartron Inc. West Sussex, U.K.) at a height of $1.5 \mathrm{~m}$. The dendrometers measured the radial variation of the stem and xylem separately. The xylem diameter changes due to reversible changes in xylem content, while the stem diameter changes due to both reversible changes in stem water content and due to irreversible cell enlargement associated with cambial growth (Chan et al., 2016; Dietrich et al., 2018). As the investigation period was late summer, the cell enlargement phase in the cambial growth of the stem had nearly ceased (see Chan et al., 2016 for the phenology of growth at the site). The radial stem measurements were recorded continuously at a one-minute time resolution.

Environmental variables, such as temperature, relative humidity, wind speed, wind direction, and the amount of incoming thermal radiation, were measured from a measurement tower located ca. $50 \mathrm{~m}$ from the measurement site (Fig. 1). The measurements were conducted at one-minute intervals. No precipitation occurred during the investigation period and neither were any dew events observed at the time of the measurements. Soil water potential was simultaneously measured with tensiometers (EQ2 Equitensiometer, Delta-T) combined to pressure transducers (TR2000A, Trans Instruments) at the depths of 5 and $15 \mathrm{~cm}$ at 15-min intervals. The data described here are openly accessible from the SMEAR station database (https://avaa.tdata.fi/web/smart/smear).

\subsection{Leaf water potential measurements}

Leaf water potential was measured at 9 time intervals during the monitoring period (Appendix 1). The top of the tree canopies was divided into three height bins for $\Psi_{\mathrm{L}}$ measurements to ensure a reliable reference for entire tree canopies: the top $2 \mathrm{~m}, 2-4 \mathrm{~m}$ from the top, and 4-6 $\mathrm{m}$ from the top. The $\Psi_{\mathrm{L}}$ samples were collected immediately after the TLS measurements. Each sample consisted of four needles or leaves that were collected in air tight plastic bags that were filled with moist air, stored in a dark and cool bag, and carried immediately to the nearby laboratory, where $\Psi_{\mathrm{L}}$ was measured using a Scholander pressure chamber (PMS-1000; PMS Instruments, Albany, OR, USA). Each $\Psi_{\mathrm{L}}$ measurement was the mean of the four samples. The $\Psi_{\mathrm{L}}$ samples were collected in approximately five minutes and the measurement of $\Psi_{\mathrm{L}}$ took approximately $15 \mathrm{~min}$ for all the samples of a single canopy.

As a dependency between canopy water status and radial stem diameter variation is known to occur (Dietrich et al., 2018), we created

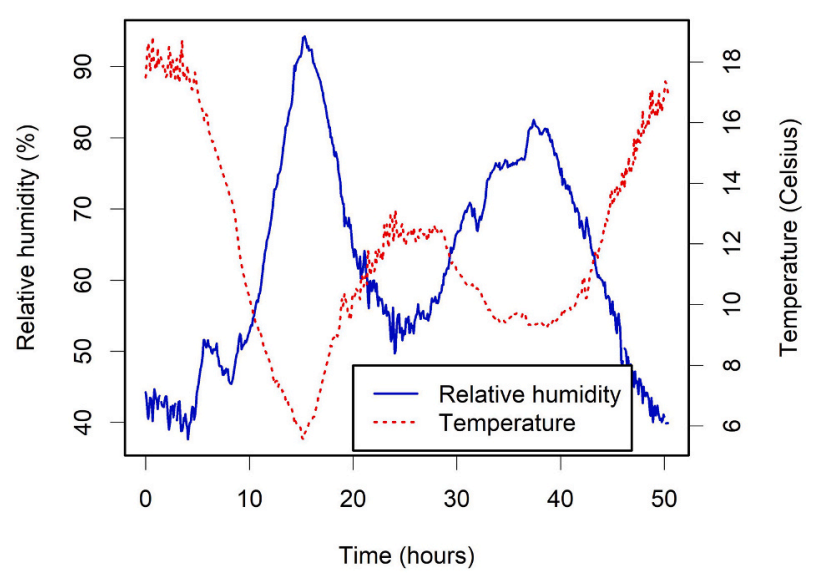

Fig. 1. Variation of temperature and relative humidity during the monitoring period. The measurements were started at 13:00 on the 29th of July and ended at 15:00 on the 31st of July 2019. 
linear regression models between $\Psi_{\mathrm{L}}$ and the radial stem diameter variation for each tree to increase the number of $\Psi_{\mathrm{L}}$ data points. Using these models, we predicted $\Psi_{\mathrm{L}}$ for each 15 time points of the TLS data. Because a lag occurs in the change in radial stem diameter after a change in $\Psi_{\mathrm{L}}$, we used a lag in creating the regression models (Sevanto et al., 2002). The predicted $\Psi_{\mathrm{L}}$ is abbreviated as $\Psi_{\mathrm{P}-\mathrm{L}}$ in the text.

\subsection{TLS measurements}

The TLS measurements were started at 13:00 on the 29th of July 2019 and ended at 15:00 in the afternoon two days later. During this monitoring period, the trees were scanned 15 times using two scanners utilizing wavelengths at $905 \mathrm{~nm}$ and $1550 \mathrm{~nm}$ (see Appendix 1 for accurate timings). Each tree was measured with a single TLS scan subsequently with both scanners from a fixed position with clear visibility to the tree crown to avoid occlusion caused by other trees. Each tree had their own scanning position and the distance to the trees varied from 11 $\mathrm{m}$ to $13 \mathrm{~m}$. The time difference between the consecutive two scans was approximately $15 \mathrm{~min}$ and one round of TLS scans (all three trees) took about one hour. The scanners used were a FARO X330 (FARO Europe GmbH \& Co. KG, Korntal-Münchingen, Germany), which operates at $1550 \mathrm{~nm}$, and a Trimble TX5 (Trimble Inc., Sunnyvale, CA, USA) operating at the $905 \mathrm{~nm}$ wavelength. These scanners have similar technical specifications: a beam divergence of $0.19 \mathrm{mrad}$, a max scan rate of 976 $\mathrm{kHz}$, and intensity recording to a digital number ( -2048 to 2033). The beam diameter at output differs slightly, with FARO X330 having a beam diameter of $2.25 \mathrm{~mm}$ and the Trimble TX5 a beam diameter of $3 \mathrm{~mm}$. Both scanners utilize phase shifting range measurements. The scanners have the same boxing; thus, the viewing angle is the same between the scanners. Both scanner resolutions were set to 0.5 , resulting in a vertical spacing of $3.07 \mathrm{~mm}$ at a $10-\mathrm{m}$ distance; the quality parameter was set to $2 \times$ (i.e. two measurements were made for each point and the resulting value was the mean of the two). We placed 11 target spheres (each with a diameter of $145 \mathrm{~mm}$ ) around the measurement tower for further scan registration. A Lambertian Spectralon reflectance panel (Labsphere, North Sutton, NH, USA) with a nominal reflectance of $40 \%$ was used as a reference target at a constant distance to normalize the laser intensity of each scan.

\subsection{Point cloud processing}

The point clouds from each measurement location were co-registered to a common arbitrary coordination system using the external sphere targets as reference points. The registration was performed in FARO Scene point cloud processing software. Each tree was then manually delineated from the individual point clouds using the CloudCompare software package (version 2.10) (Dewez et al., 2016). The calibration of intensity was conducted to reduce variation caused by factors such as temperature and distance. The intensity correction workflow followed the procedure presented in Junttila et al. (2019), which included distance and logarithmic corrections and the normalization of intensity with a reflectance panel with known reflectance. The intensity measured from the reference panel showed a standard deviation between 10 and 13 in raw intensity values. The distance correction was performed using a 10th degree polynomial function that was modelled with empirical data concerning the intensity and distance of the scanner (see Appendix 1 for model parameters). The raw intensity scale of the scanner was found to be logarithmic. Thus, a linearization of the intensity scale was necessary using empirical relationships between reflectance and raw intensity. Further details are provided in Junttila et al. (2019).

\subsection{Point cloud segmentation}

Each tree canopy was segmented from the point clouds to mainly include needle or leaf points into the analysis. Segmentation was based on a minimum height that was determined visually. The minimum heights that were used to segment the canopies were $9.9 \mathrm{~m}, 11.5 \mathrm{~m}$, and $10 \mathrm{~m}$, for pine 1 , pine 2 , and birch, respectively. We included all the points from the canopy into the analysis to avoid interfering with the intensity data distribution at the tree level and to ensure consistency of the data between subsequent measurements of the time series. Thus, no classification to branch and needle or leaf points was carried out. Based on a mean of a random sample of 15,000 points, the birch leaf points showed a calibrated intensity of $0.56(905 \mathrm{~nm})$ and $0.18(1550 \mathrm{~nm})$, while branch points had an intensity of $0.48(905 \mathrm{~nm})$ and 0.28 (1550 $\mathrm{nm})$. The pine needle points had an intensity of $0.31(905 \mathrm{~nm})$ and 0.12 $(1550 \mathrm{~nm})$, and the stem points intensity of $0.45(905 \mathrm{~nm})$ and 0.37 $(1550 \mathrm{~nm})$. The number of points in the resulting point clouds that were used in the analysis varied between 220,000 and 450,000 between the trees and observation times.

\subsection{Explanatory intensity metrics}

A variety of intensity metrics was calculated for each segmented point cloud (Table 2). These metrics describe the distribution of intensity values within a given point cloud at different wavelengths. The metrics were calculated for the 905 and $1550 \mathrm{~nm}$ wavelengths separately. As the calculation of NDI for single 3D points was complicated due to slight movements of the branches between consecutive scans, NDI was calculated based on the distribution of intensity values in the canopy. The calculation of NDI was performed using percentiles (10th, 20th, 30th... 90th) and means of the $905 \mathrm{~nm}$ and $1550 \mathrm{~nm}$ wavelengths (Eq. (3)). All the intensity metrics are shown in Table 2.

$N D I=\frac{I_{905}-I_{1550}}{I_{905}+I_{1550}}$

\subsection{Statistical analysis}

Student's two-sided $t$-tests were used to assess the difference in $\Psi_{\mathrm{L}}$ at different heights. Linear regression modelling was used to assess the relationships between the intensity metrics and $\Psi_{\mathrm{L}}$. We used reduced major axis regression (model 2 regression), because both variables contain measurement error (Davis and Sampson, 1986). Regression models were created using both the measured and predicted $\Psi_{\mathrm{L}}$ as dependent variables. Normality of the data was tested using the Shapiro-Wilkinson test (Hanusz and Tarasińska, 2015). The coefficient of determination $\left(R^{2}\right)$ and root-mean-square-error (RMSE) were calculated to assess the estimation accuracy of the intensity variables. All of the statistical analyses were carried out within the R package (R Core Team, 2015).

\section{Table 2}

Description of the calculated intensity metrics. In the table, i denotes the wavelength followed by the name of the metric. For example "1550_mean" means average intensity at the $1550 \mathrm{~nm}$ wavelength. Respectively, normalized difference index (NDI) metrics are followed by the percentile used in the calculation of NDI. For example, "NDI_p20" means the metric has been calculated using the 20th percentile of the $905 \mathrm{~nm}$ and $1550 \mathrm{~nm}$ wavelengths).

\begin{tabular}{ll}
\hline Metric & Description \\
\hline i_mean & Average intensity \\
i_std & Standard deviation of intensity \\
i_p10, i_p20,.. & Multiple-of-10 percentiles (10th through 90th) of the \\
i_p90 & intensity distribution \\
i_max & Maximum intensity \\
i_min & Minimum intensity \\
i_kur & Kurtosis of the intensity distribution (Davies and Goldsmith, \\
& 1976) \\
i_ske & Skewness of the intensity distribution (Davies and Goldsmith, \\
& 1976) \\
i_entropy & Shannon diversity index (entropy) of the intensity \\
& distribution (Shannon, 2001) \\
i_range & Difference between maximum and minimum intensity \\
i_D05, i_D25, i_D50, & Density variables: the 95th percentile divided by the 5th, \\
i_D75 & 25th, 50th, and 75th percentiles, respectively. \\
\hline
\end{tabular}




\section{Results}

\subsection{Variation in leaf water potential based on the Scholander pressure} chamber

The lowest $\Psi_{\mathrm{L}}$ values were observed on the day the measurements were begun (Fig. 2). Fig. 2 shows a minor decreasing trend in $\Psi_{\mathrm{L}}$ higher in the tree for the silver birch, but no significant differences in $\Psi_{\mathrm{L}}$ between the different height layers during the monitoring period. Soil water potential varied between -0.05 and $-0.08 \mathrm{MPa}$ at the $15-\mathrm{cm}$ depth and between $-0.15 \mathrm{MPa}$ and $-0.21 \mathrm{MPa}$ at the $5-\mathrm{cm}$ depth.

\subsection{Leaf water potential prediction based on stem diameter} measurements

A strong linear relationship was observed between $\Psi_{\mathrm{L}}$ and stem diameter variation for each tree (Fig. 3). The strongest relationship was found using a 90-min time lag between the $\Psi_{\mathrm{L}}$ and stem diameter measurement.

\subsection{Assessing the relationships between leaf water potential and intensity metrics}

The intensity metrics explained a significant proportion of the variation in $\Psi_{\mathrm{L}}$ (Fig. 4). The best-predicting TLS intensity variables explained $70 \%, 71 \%$, and $77 \%$ of the variation in $\Psi_{\mathrm{L}}$ in pine 1 , pine 2 , and the birch, respectively (Table 3). Generally, the strongest predictors were mainly distribution features of the $905 \mathrm{~nm}$ wavelength, but the distribution of $1550 \mathrm{~nm}$ showed similar explanatory power for pine 1 . The D25 intensity feature of the $905 \mathrm{~nm}$ wavelength explained $77 \%$ of the variation in $\Psi_{\mathrm{L}}$ with observations from all of the trees in the prediction model. However, the distribution of intensity metrics using

\section{Pine 1}

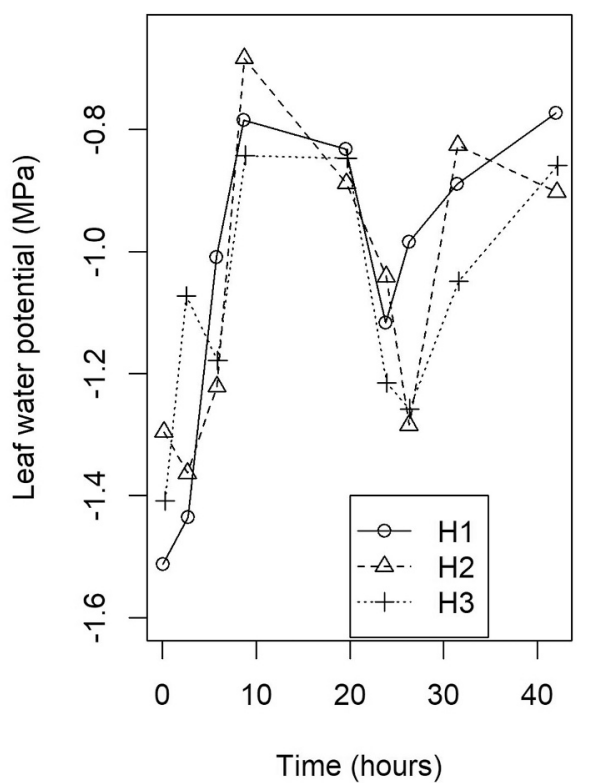

Pine 2

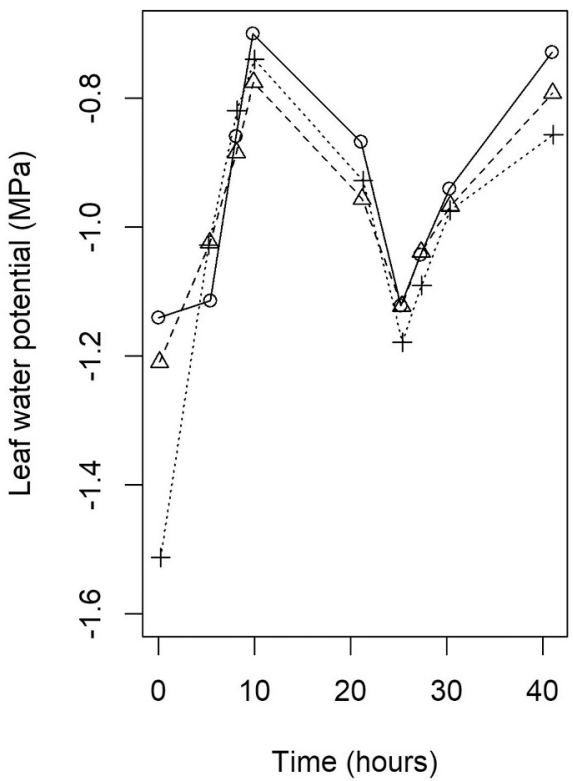

Birch

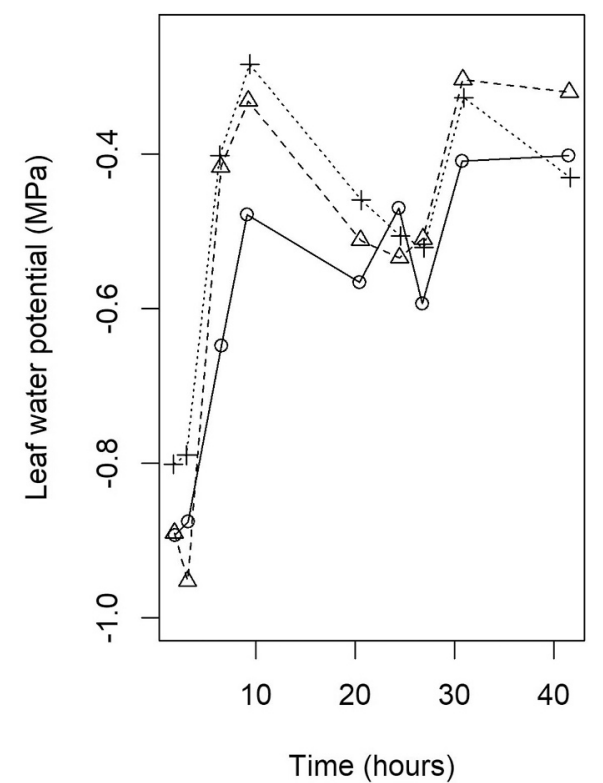

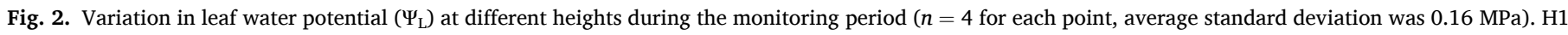

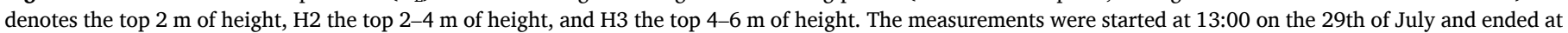
15:00 on the 31st of July 2019.

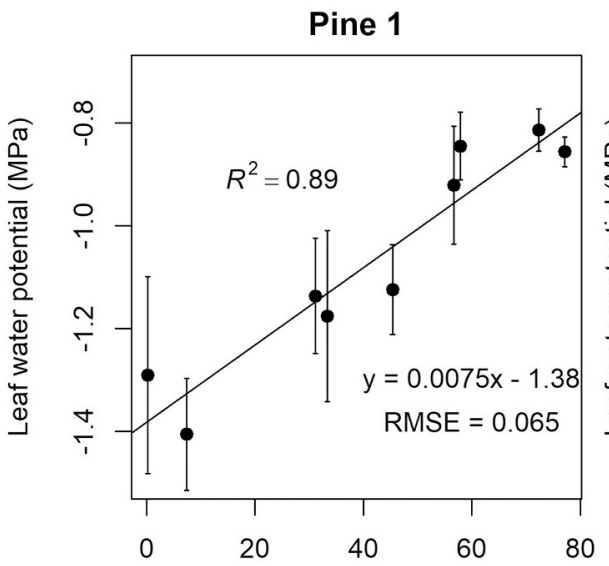

Stem diameter variation $(\mu \mathrm{m})$
Pine 2

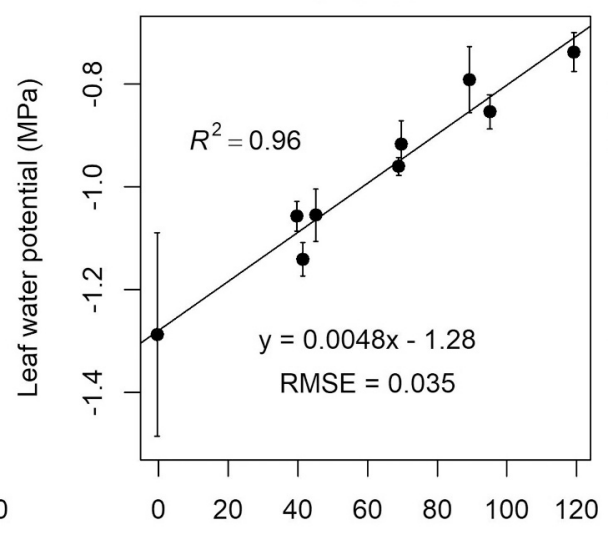

Stem diameter variation $(\mu \mathrm{m})$
Birch

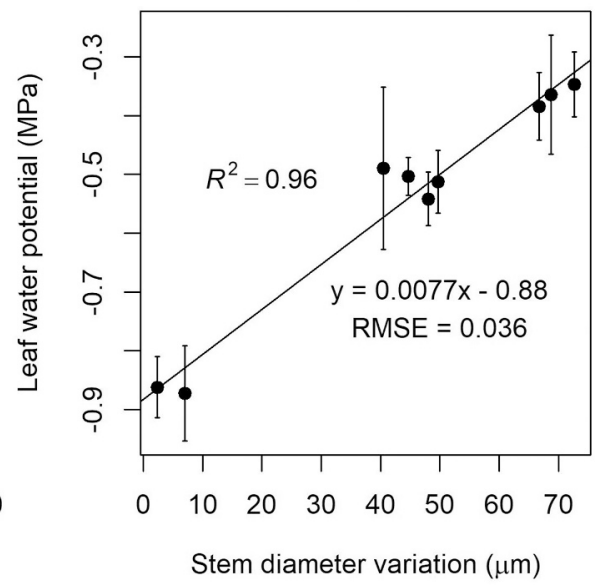

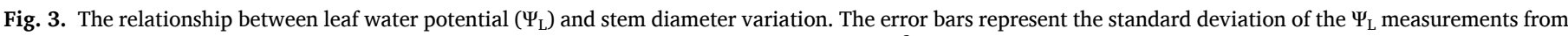

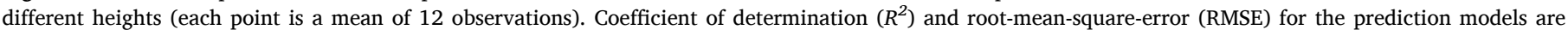
also presented. 

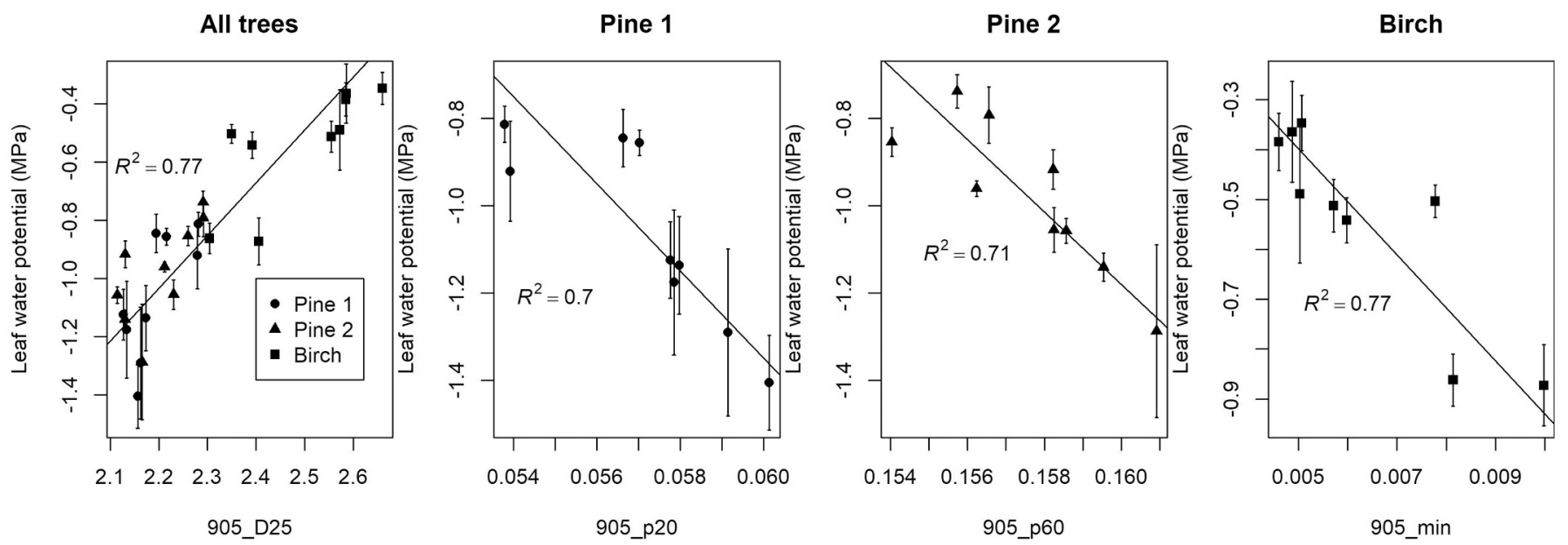

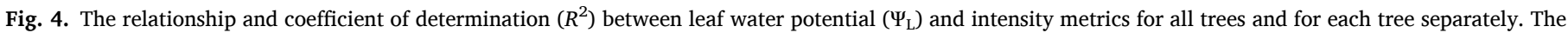

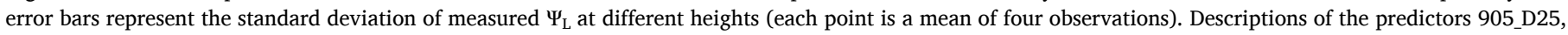
905_p20, 905_p60, and 905_min is provided in Table 2.

Table 3

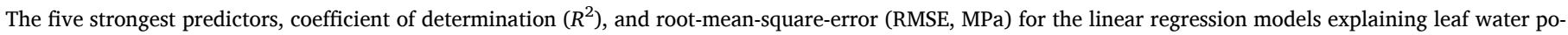

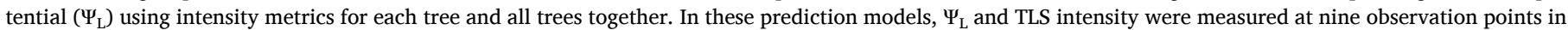
time. A description of the predictors is provided in Table 2.

\begin{tabular}{|c|c|c|c|c|c|c|c|c|}
\hline \multicolumn{3}{|l|}{ Pine 1} & \multicolumn{3}{|l|}{ Pine 2} & \multicolumn{3}{|l|}{ Birch } \\
\hline Predictor & $R^{2}$ & RMSE & Predictor & $R^{2}$ & RMSE & Predictor & $R^{2}$ & RMSE \\
\hline 905_p20 & 0.70 & 0.111 & 905_p60 & 0.71 & 0.089 & 905_min & 0.77 & 0.089 \\
\hline 1550_p60 & 0.65 & 0.119 & 905_p50 & 0.71 & 0.089 & 1550_min & 0.70 & 0.102 \\
\hline 905_p30 & 0.65 & 0.120 & 905_p40 & 0.71 & 0.089 & 905_p05 & 0.65 & 0.109 \\
\hline 1550_p70 & 0.62 & 0.124 & 905_mean & 0.66 & 0.097 & 905_p10 & 0.60 & 0.117 \\
\hline 1550_p80 & 0.56 & 0.134 & 905_p70 & 0.66 & 0.097 & 905_D25 & 0.53 & 0.128 \\
\hline \multicolumn{9}{|l|}{ All trees } \\
\hline Predictor & & & & $R^{2}$ & & & & RMSE \\
\hline 905_D25 & & & & 0.77 & & & & 0.141 \\
\hline 905_D05 & & & & 0.58 & & & & 0.189 \\
\hline $905 \_s t d$ & & & & 0.58 & & & & 0.190 \\
\hline 905_D50 & & & & 0.55 & & & & 0.196 \\
\hline 905_p95 & & & & 0.54 & & & & 0.199 \\
\hline
\end{tabular}

observations from all trees in the same model were not normally distributed, which is against the assumptions of linear regression, likely causing overestimation of the relationship. This was due to the uneven distribution of tree species in the samples.

\subsection{Assessing the relationships between predicted leaf water potential and intensity metrics}

When we predicted $\Psi_{\mathrm{L}}$ for all the 15 observation points in time (See 3.2) and used $\Psi_{\mathrm{P}-\mathrm{L}}$ as a dependent variable in our linear regression models, we obtained similar results as those presented in 3.3. On average, the $905 \mathrm{~nm}$ wavelength features were able to explain a larger proportion of the variation in predicted $\Psi_{\mathrm{L}}$ than the $1550 \mathrm{~nm}$ and NDI features with the exception of pine 1 (Table 4, Fig. 5). For the birch, the lowest part of the $905 \mathrm{~nm}$ intensity distribution was most sensitive to variation in $\Psi_{\mathrm{L}}$ with the 905_min, 905_p05, and 905_p10 features among the strongest predictors. Whereas the strongest predictors for the pines varied around the mean of the intensity distribution (i.e., p30, p40, p50, p60 features). Again we note that the intensity variables of all the trees pooled together were not normally distributed according to the ShapiroWilkinson test due to the different numbers of pines and birch in the data.

\section{Discussion}

The main aim of this study was to investigate how much of the diurnal variation in $\Psi_{\mathrm{L}}$ within Scots pine and silver birch trees can be explained using TLS intensity measurements. Our results showed that TLS intensity at both $905 \mathrm{~nm}$ and $1550 \mathrm{~nm}$ wavelengths increased due to decreased leaf water content, and that a time series of TLS intensity measurements can capture from $70 \%$ to $77 \%$ of the variation in measured $\Psi_{\mathrm{L}}$ for individual trees. Our destructive $\Psi_{\mathrm{L}}$ measurements were complemented with estimated $\Psi_{\mathrm{L}}$ values that were based on stem diameter change measurements and existing knowledge on the time lag between the change in $\Psi_{\mathrm{L}}$ and stem diameter (Lintunen et al., 2020). The time lag of $90 \mathrm{~min}$ that we used is in line with earlier results (Sevanto et al., 2002).

TLS intensity showed a relatively strong relationship with $\Psi_{\mathrm{L}}\left(R^{2}\right.$ of $0.56-0.77)$ for individual trees, especially at the $905 \mathrm{~nm}$ wavelength (See Table 3). This result is partly contrary to previous research, since the $1550 \mathrm{~nm}$ wavelength has been shown to be generally more sensitive to leaf water content than the $905 \mathrm{~nm}$ wavelength (Ceccato et al., 2001). Although the $905 \mathrm{~nm}$ wavelength can exhibit changes due to leaf water content (Penuelas et al., 1997), other factors may have contributed to the behaviour of the $905 \mathrm{~nm}$ wavelength in this study.

The amount of water in leaves is linked to their leaf area (Juneau and 
Table 4

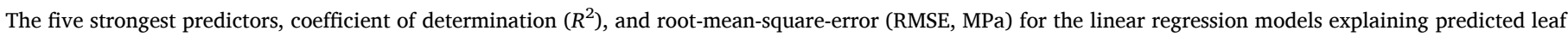

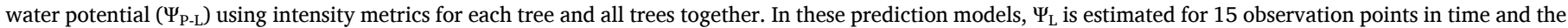

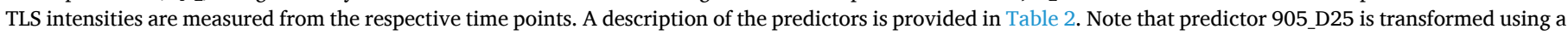
logarithm $\left(\log \left(905 \_D 25\right)\right)$.

\begin{tabular}{|c|c|c|c|c|c|c|c|c|}
\hline \multicolumn{3}{|l|}{ Pine 1} & \multicolumn{3}{|l|}{ Pine 2} & \multicolumn{3}{|l|}{ Birch } \\
\hline Predictor & $R^{2}$ & RMSE & Predictor & $R^{2}$ & RMSE & Predictor & $R^{2}$ & RMSE \\
\hline 1550_p50 & 0.56 & 0.170 & 905_p40 & 0.58 & 0.139 & 905_min & 0.74 & 0.109 \\
\hline 905_D75 & 0.53 & 0.175 & 905_entropy & 0.58 & 0.139 & 905_p05 & 0.64 & 0.127 \\
\hline 1550_p40 & 0.53 & 0.176 & 905_mean & 0.56 & 0.142 & 905_entropy & 0.63 & 0.131 \\
\hline 1550_p30 & 0.50 & 0.182 & 905_p30 & 0.56 & 0.143 & 905_p10 & 0.62 & 0.132 \\
\hline 1550_p60 & 0.49 & 0.182 & 1550_D50 & 0.53 & 0.146 & 905_p20 & 0.50 & 0.151 \\
\hline \multicolumn{9}{|l|}{ All trees } \\
\hline Predictor & & & & $R^{2}$ & & & & $R M S E$ \\
\hline $\log \left(905 \_D 25\right)$ & & & & 0.70 & & & & 0.180 \\
\hline 905_D50 & & & & 0.49 & & & & 0.236 \\
\hline 905_D05 & & & & 0.47 & & & & 0.241 \\
\hline 905_std & & & & 0.47 & & & & 0.242 \\
\hline NDI_p90 & & & & 0.46 & & & & 0.244 \\
\hline
\end{tabular}
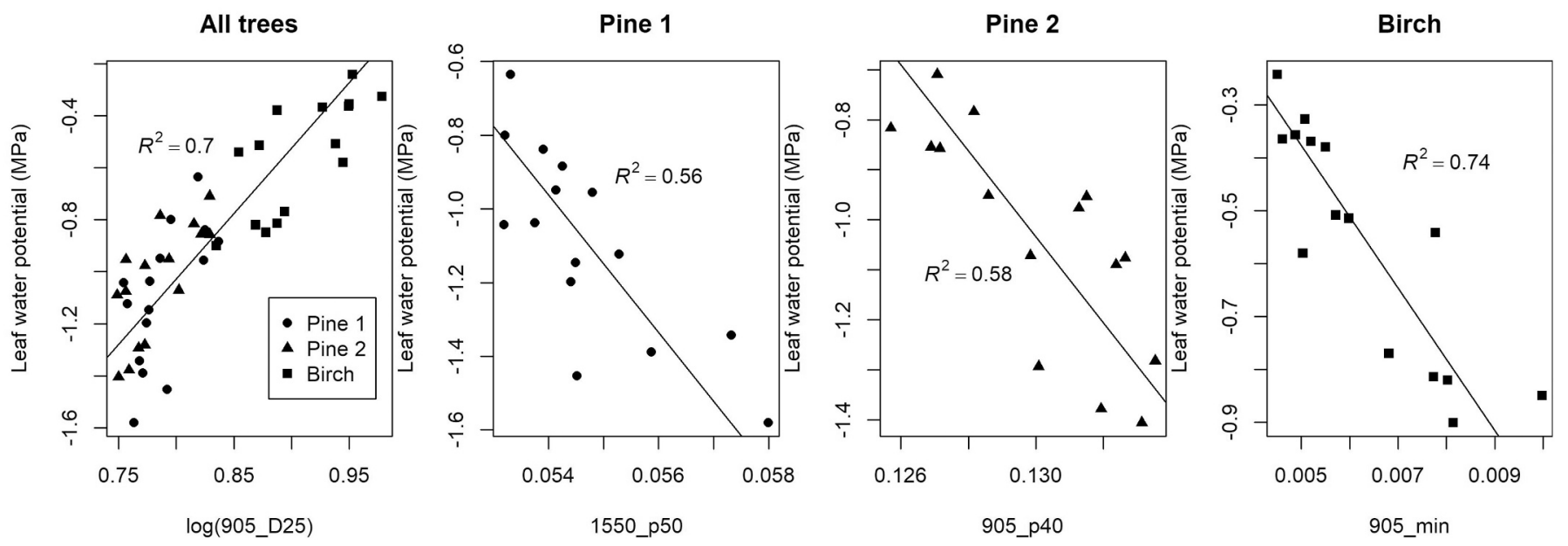

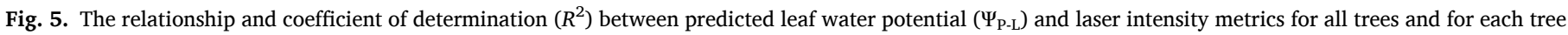

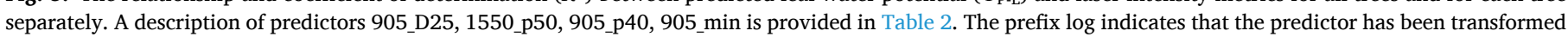
using the logarithm function.

Tarasoff, 2012), thus, variation in the size of needles or leaves could have resulted in variation in TLS intensity. Another possible factor that could have co-occurred with changes in leaf water content is variation in leaf angle distribution. Reduced amount of water within leaves also affects their mass, which can affect the angle of leaves and needles relative to the branches holding them. In addition, diurnal branch movement has been detected using TLS and it could also affect the TLS intensity distribution of tree canopies within diurnal time scales (Puttonen et al., 2016). Since leaves tend to strongly reflect near-infrared light, where the $905 \mathrm{~nm}$ wavelength is situated, we could anticipate that any changes in the dimensions or angles of leaves would affect the $905 \mathrm{~nm}$ wavelength more than the $1550 \mathrm{~nm}$ wavelength. On the other hand, the TLS intensity difference between foliage and stem returns is greater for the $1550 \mathrm{~nm}$ wavelength, which is largely affected by water content (Ceccato et al., 2001; Feret et al., 2019). The stem points showed a two-fold higher reflectance compared to foliage points for the $1550 \mathrm{~nm}$ wavelength (average TLS intensity of needles 0.12 vs. 0.37 for the stem), but little difference was found between the two for the $905 \mathrm{~nm}$ wavelength (average TLS intensity of needles 0.31 vs. 0.45 for the stem). Thus, any change in the distribution of stem and foliage points within a sample caused, for example by altered leaf angle distribution, would be seen as a greater change in the TLS intensity distribution of the $1550 \mathrm{~nm}$ wavelength than the $905 \mathrm{~nm}$ wavelength. Therefore, without measurements of the aforementioned factors, it is difficult to state if the relationships between TLS intensity and $\Psi_{\mathrm{L}}$ are found solely on changes in leaf water content, but further studies should address the interaction of TLS intensity and diurnal variation of canopy properties more in-depth. However, based on the observed relationship between $\Psi_{\mathrm{L}}$ and TLS intensity in the field, TLS intensity measurements seemed relatively insensitive to the constantly varying illumination conditions which, based on previous research, hinder the use of passive remote sensing methods for many forest monitoring applications (Cheng et al., 2014; Nichol et al., 2006).

When estimating $\Psi_{\mathrm{L}}$, we observed differences in the performance of the intensity metrics between the tree species. For Scots pines, the intensity metrics that were strongest predictors in explaining variation in $\Psi_{\mathrm{L}}$ were found around the middle of the intensity distribution at both the $905 \mathrm{~nm}$ and $1550 \mathrm{~nm}$ wavelengths varying between the 20th and the 60th percentile of the distribution. For silver birch, the intensity metrics that were strongest predictors in explaining variation in $\Psi_{\mathrm{L}}$ were in the lowest part of the intensity distribution of both the $905 \mathrm{~nm}$ and $1550 \mathrm{~nm}$ wavelengths, the $905 \mathrm{~nm}$ wavelength showing distinctly better performance. The differences in the intensity metrics explaining the variation in $\Psi_{\mathrm{L}}$ between trees are likely due to the varying structure of the tree crowns, difference in leaf shape (coniferous vs. deciduous), and differences in the numbers of needle/leaf and stem/branch points in the segmented point clouds. 
Our preliminary tests indicated that filtering of stray points and detailed segmentation of the point clouds caused the relationship between intensity and $\Psi_{\mathrm{L}}$ to substantially decrease, which was likely due to the effect of these procedures on the intensity distribution. Therefore, we suggest that caution should be used when filtering, segmenting, and classifying point clouds as these procedures can have a significant impact on the TLS intensity distribution, especially when using a time series of intensity observations from the same target, as we did in this study. This has not been reported before. Thus, further studies should investigate the link between the stability of intensity distributions and different point cloud modifications.

We used a simple segmentation of the canopy and did not separate leaf and stem points in this study. We also did not filter stray or "ghost" points that commonly result from the laser hitting the edges of a target (Eitel et al., 2010). Although the leaf material classification could be expected to improve the estimation accuracy of $\Psi_{\mathrm{L}}$, the correlation between TLS intensity metrics and $\Psi_{\mathrm{L}}$ was already strong using the methods applied in this study. However, for operational applications that could be used to predict $\Psi_{\mathrm{L}}$ over time for a large number of trees in forests, robust methods for separating leaf points would be required. Our results are likely influenced by the large amount of intensity observations from each tree canopy, which results in a more stable intensity distribution than that achievable for individual branches or leaves. The trees were also scanned each time from the same position, which in principle should result in a nearly equal number of stem and leaf points in the point clouds.

Earlier studies have found that NDI metrics have been stronger predictors for EWT than single-wavelength metrics, because another wavelength has been able to normalize a part of the variation in TLS intensity caused by varying incidence angle and leaf structure (Elsherif et al., 2019b; Junttila et al., 2019; Junttila et al., 2018). In this study, the NDI metrics did not provide any improvement compared to single-wavelength metrics in estimating $\Psi_{\mathrm{L}}$, which may be caused by differences in the design of this and other experiments. The main differences compared to previous studies were: 1 ) the utilization of a dense time series to monitor diurnal variation in leaf water status instead of single observations of different leaves or trees with varying leaf water content, 2) the nondestructive nature of the research design (i.e. same trees were measured multiple times), and 3) the estimation of $\Psi_{\mathrm{L}}$ instead of EWT. Thus, direct comparisons to previous studies should not be made. The reason why the NDI metrics did not perform as well as single-wavelength metrics in the estimation of $\Psi_{\mathrm{L}}$ was likely firstly caused by the nearly constant leaf/needle structure during the monitoring period, which reduces the need for leaf structural normalization with NDI metrics (Junttila et al., 2018). Another likely reason is that within the tree canopies the incidence angle of leaves and needles should stay relatively constant at the canopy-level, and therefore the single wavelength intensity features are less influenced by the incidence angle. Single-wavelength metrics have also been strong predictors of EWT for single species in a drying experiment (Junttila et al., 2016). Structural differences in foliage have a greater effect on intensity if a larger number of trees are monitored simultaneously. Secondly, despite the wind speed was low during the monitoring period, slight movements of the leaves and branches occurred between the subsequent scans at the $905 \mathrm{~nm}$ and $1550 \mathrm{~nm}$ wavelengths, which may affect the stability of the NDI metrics through the time series. Thirdly, we used TLS intensity to measure the change in leaf water content and to derive $\Psi_{\mathrm{L}}$ instead of direct EWT estimation.

However, in our controlled experiment, TLS intensity proved able to explain $61-78 \%$ of the within-tree and between-tree variation in $\Psi_{\mathrm{L}}$. The best-performing intensity features were mainly density features of the $905 \mathrm{~nm}$ wavelength (905_D25, 905_D05, 905_D50) that describe the variation in TLS intensity within a tree canopy. In other words, the changes in the shape of the intensity distribution due to varying $\Psi_{\mathrm{L}}$ have been similar between trees and tree species, encouraging further studies towards developing a general model that could estimate $\Psi_{\mathrm{L}}$ using TLS intensity measurements. The finding that density features outperformed other TLS intensity features can be partly explained by the ability of density features in normalizing TLS intensity differences between trees arising from calibration issues, because the density features are not sensitive to the absolute position of the TLS intensity distribution. We should note that the numbers of trees and samples were rather limited in our study for evaluating the capability of TLS intensity time series in estimating $\Psi_{\mathrm{L}}$ for trees of varying ages, species, and structures growing in various ecoregions, but based on our results, a clear correlation appears to occur between TLS intensity and $\Psi_{\mathrm{L}}$.

Non-destructive measurements of $\Psi_{\mathrm{L}}$ using TLS intensity at larger scales could be feasible in the future if technical challenges can be overcome, which would enable tree stress detection and the investigation of canopy water dynamics at larger scales. Despite the fairly strong agreement between $\Psi_{\mathrm{L}}$ and TLS intensity, the best performing intensity features varied among the three measured trees in our study, which a sign of mild inconsistency of the TLS intensity distributions between the trees. Terrestrial laser scanning intensity measurements require calibration (Kaasalainen et al., 2011; Kaasalainen et al., 2009), but the lack of reliable calibration methods hinders the use of TLS intensity information on a larger scale. Firstly, the main challenges remain in the distance and incidence angle calibrations of TLS intensity, which require development to allow more robust measurements in varying forest conditions. Current calibration methods are unable to account for the differences in backscattered reflectance that are caused by small targets that do not cover the laser footprint entirely. This should be especially considered when measuring coniferous species with needles, which tend to be smaller than the laser footprint, because the relationship between laser intensity and distance is determined by the target size and a smaller amount of backscattered light is received small targets (Korpela, 2017). Secondly, accurate classification of foliage from woody material is required for assessing the canopy reflectance directly instead of using TLS intensity value distribution features that include woody material. A rigorous intensity calibration method would pave the way towards applications in tree and plant stress detection using also laser scanning from moving platforms such as airborne or mobile laser scanning that would enable large-scale monitoring of $\Psi_{\mathrm{L}}$ using diurnal measurements, which are currently challenging. However, based on the results of this study and earlier work (Junttila et al., 2019), static TLS intensity measurements from tree crowns may reveal changes caused by e.g. altered water content despite the challenges in the calibration.

The theoretical background of the link between relative water content and $\Psi_{\mathrm{L}}$ is strong, but there are also certain limitations to the capability of leaf water content in explaining $\Psi_{\mathrm{L}}$ variation. The used estimation approach is based on the relationship between $\Psi_{\mathrm{L}}$ and relative water content. However, relative water content is not the only variable affecting $\Psi_{\mathrm{L}}$ and osmotic potential may also affect $\Psi_{\mathrm{L}}$, especially at longer time intervals or during extreme events such as drought (Bartlett et al., 2012; Nobel, 1999). Therefore, for longer time intervals (for example, month, season, year), the estimation accuracy of $\Psi_{\mathrm{L}}$ using TLS intensity is likely constrained by the influence of changes in osmotic potential.

We investigated the capability of TLS intensity in capturing the diurnal variation of $\Psi_{\mathrm{L}}$. Earlier studies that have utilized TLS intensity in plant water status estimation have concentrated on estimating EWT, which may vary greatly within tree canopies and is strongly related to leaf mass per area (LMA). Leaf mass per area varies greatly between species and within species depending on environmental conditions such as light and temperature (Poorter et al., 2009). Therefore, EWT is less useful in understanding plant water status compared to $\Psi_{\mathrm{L}}$ (Elsherif et al., 2019b; Junttila et al., 2019). Although intensity metrics explained a large part of the variation in $\Psi_{\mathrm{L}}$ in our controlled experiment including three trees, there is still limited knowledge on how consistent the relation between $\Psi_{\mathrm{L}}$ and intensity metrics is within and between the tree communities. Theoretically, TLS can measure tens of tree canopies with a single easy-to-repeat scan and the ability of estimating the $\Psi_{\mathrm{L}}$ of these canopies would enable the measurement of $\Psi_{\mathrm{L}}$ at unprecedented spatial and temporal scales, which may help us further understand the 
movement of water within the soil-plant-atmosphere continuum and the effect of a warmer and drier climate on our ecosystems.

\section{Declaration of Competing interest}

None.

\section{Acknowledgements}

This work was supported by the Faculty of Agriculture and Forestry of the University of Helsinki, the Academy of Finland under [grant numbers 307362, 316096/320075, and 330422], and the Finnish Cultural Foundation.

\section{Appendix 1}

In this appendix we present the detailed schedule of the TLS and $\Psi_{\mathrm{L}}$ measurements and the model parameters that were used to correct for the logarithmic behaviour of the TLS intensity.

Table 1

The starting time for each round of TLS scans and whether leaf water potential was measured or not.

\begin{tabular}{llll}
\hline Scan number & Time & Date & $\Psi_{\mathrm{L}}$ was measured \\
\hline 1 & $13: 00$ & 29.7 .2019 & yes \\
2 & $15: 20$ & 29.7 .2019 & yes \\
3 & $18: 35$ & 29.7 .2019 & yes \\
4 & $21: 30$ & 29.7 .2019 & yes \\
5 & $06: 12$ & 30.7 .2019 & no \\
6 & $8: 22$ & 30.7 .2019 & yes \\
7 & $12: 37$ & 30.7 .2019 & yes \\
8 & $15: 05$ & 30.7 .2019 & yes \\
9 & $18: 04$ & 30.7 .2019 & no \\
10 & $19: 09$ & 30.7 .2019 & yes \\
11 & $21: 37$ & 30.7 .2019 & no \\
12 & $05: 51$ & 31.7 .2019 & yes \\
13 & $09: 45$ & 31.7 .2019 & no \\
14 & $12: 22$ & 31.7 .2019 & no \\
15 & $14: 04$ & 31.7 .2019 & no \\
\hline
\end{tabular}

Table 2

The polynomial model parameters used for distance correction of TLS intensity.

\begin{tabular}{|c|c|c|c|c|c|c|}
\hline \multicolumn{7}{|c|}{ Trimble TX5 } \\
\hline Intercept & $a_{1}$ & $a_{2}$ & $a_{3}$ & $a_{4}$ & $a_{5}$ & $a_{6}$ \\
\hline 1826.5 & -142.5 & 126.0 & 0.3037 & -75.7555 & 65.4323 & -1.75 \\
\hline$a_{7}$ & $a_{8}$ & $a_{9}$ & $a_{10}$ & & & \\
\hline-19.41 & 8.4852 & 26.2545 & -21.18 & & & \\
\hline \multicolumn{7}{|c|}{ FARO X330 } \\
\hline Intercept & $a_{1}$ & $a_{2}$ & $a_{3}$ & $a_{4}$ & $a_{5}$ & $a_{6}$ \\
\hline 1550.813 & -214.561 & 167.473 & -58.98 & -54.93 & 121.396 & -112.53 \\
\hline$a_{7}$ & $a_{8}$ & $a_{9}$ & $a_{10}$ & & & \\
\hline 51.282 & 1.697 & -32.113 & 25.183 & & & \\
\hline
\end{tabular}

\section{References}

Antonarakis, A.S., Richards, K.S., Brasington, J., Muller, E., 2010. Determining leaf area index and leafy tree roughness using terrestrial laser scanning. Water Resour. Res. https://doi.org/10.1029/2009wr008318.

Baluja, J., Diago, M.P., Balda, P., Zorer, R., Meggio, F., Morales, F., Tardaguila, J., 2012. Assessment of vineyard water status variability by thermal and multispectral imagery using an unmanned aerial vehicle (UAV). Irrig. Sci. https://doi.org/ 10.1007/s00271-012-0382-9.

Bartlett, M.K., Scoffoni, C., Sack, L., 2012. The determinants of leaf turgor loss point and prediction of drought tolerance of species and biomes: a global meta-analysis. Ecol. Lett. 15, 393-405. https://doi.org/10.1111/j.1461-0248.2012.01751.x.

Beer, C., Reichstein, M., Tomelleri, E., Ciais, P., Jung, M., Carvalhais, N., Rödenbeck, C. Arain, M.A., Baldocchi, D., Bonan, G.B., Bondeau, A., Cescatti, A., Lasslop, G., Lindroth, A., Lomas, M., Luyssaert, S., Margolis, H., Oleson, K.W., Roupsard, O., Veenendaal, E., Viovy, N., Williams, C., Woodward, F.I., Papale, D., 2010. Terrestrial gross carbon dioxide uptake: global distribution and covariation with climate. Science 329, 834-838. https://doi.org/10.1126/science.1184984.

Bei, R.D.E., de Bei, R., Cozzolino, D., Sullivan, W., Cynkar, W., Fuentes, S., Dambergs, R., Pech, J., Tyerman, S., 2011. Non-destructive measurement of grapevine water potential using near infrared spectroscopy. Aust. J. Grape Wine Res. https://doi.org/ 10.1111/j.1755-0238.2010.00117.x.

Ceccato, P., Flasse, S., Tarantola, S., Jacquemoud, S., Grégoire, J.-M., 2001. Detecting vegetation leaf water content using reflectance in the optical domain. Remote Sens. Environ. https://doi.org/10.1016/s0034-4257(01)00191-2.
Chan, T., Hölttä, T., Berninger, F., Mäkinen, H., Nöjd, P., Mencuccini, M., Nikinmaa, E., 2016. Separating water-potential induced swelling and shrinking from measured radial stem variations reveals a cambial growth and osmotic concentration signal. Plant Cell Environ. 39, 233-244. https://doi.org/10.1111/pce.12541.

Cheng, T., Riaño, D., Ustin, S.L., 2014. Detecting diurnal and seasonal variation in canopy water content of nut tree orchards from airborne imaging spectroscopy data using continuous wavelet analysis. Remote Sens. Environ. https://doi.org/10.1016/ j.rse.2013.11.018.

Cochard, H., Coll, L., Le Roux, X., Améglio, T., 2002. Unraveling the effects of plant hydraulics on stomatal closure during water stress in walnut. Plant Physiol. 128, 282-290. https://doi.org/10.1104/pp.010400.

Cohen, Y., Alchanatis, V., Meron, M., Saranga, Y., Tsipris, J., 2005. Estimation of leaf water potential by thermal imagery and spatial analysis. J. Exp. Bot. 56, 1843-1852. https://doi.org/10.1093/jxb/eri174.

Colombo, R., Meroni, M., Marchesi, A., Busetto, L., Rossini, M., Giardino, C., Panigada, C., 2008. Estimation of leaf and canopy water content in poplar plantations by means of hyperspectral indices and inverse modeling. Remote Sens. Environ. https://doi.org/10.1016/j.rse.2007.09.005.

Cotrozzi, L., Couture, J.J., Cavender-Bares, J., Kingdon, C.C., Fallon, B., Pilz, G., Pellegrini, E., Nali, C., Townsend, P.A., 2017. Using foliar spectral properties to assess the effects of drought on plant water potential. Tree Physiol. 37, 1582-1591. https://doi.org/10.1093/treephys/tpx106.

Davis, J.C., Sampson, R.J., 1986. Statistics and data analysis in geology (Vol. 646). Wiley, New York.

Dai, A., 2013. Increasing drought under global warming in observations and models. Nat. Clim. Chang. https://doi.org/10.1038/nclimate1633. 
Danson, F.M., Steven, M.D., Malthus, T.J., Clark, J.A., 1992. High-spectral resolution data for determining leaf water content. Int. J. Remote Sens. https://doi.org/ 10.1080/01431169208904049.

Dassot, M., Constant, T., Fournier, M., 2011. The use of terrestrial LiDAR technology in forest science: application fields, benefits and challenges. Ann. For. Sci. https://doi. org/10.1007/s13595-011-0102-2.

Davies, O.L., Goldsmith, P.L., 1976. Statistical Methods in Research and Production.

De Swaef, T., De Schepper, V., Vandegehuchte, M.W., Steppe, K., 2015. Stem diameter variations as a versatile research tool in ecophysiology. Tree Physiol. 35, 1047-1061. https://doi.org/10.1093/treephys/tpv080.

Dewez, T.J.B., Girardeau-Montaut, D., Allanic, C., Rohmer, J., 2016. Facets : a CLOUDCOMPARE plugin to extract geological planes from unstructured 3D point clouds. Int. Archiv. Photogram. https://doi.org/10.5194/isprs-archives-xli-b5-799. 2016.

Dietrich, L., Zweifel, R., Kahmen, A., 2018. Daily stem diameter variations can predict the canopy water status of mature temperate trees. Tree Physiol. 38, 941-952. https://doi.org/10.1093/treephys/tpy023.

Eitel, J.U.H., Vierling, L.A., Long, D.S., 2010. Simultaneous measurements of plant structure and chlorophyll content in broadleaf saplings with a terrestrial laser scanner. Remote Sens. Environ. https://doi.org/10.1016/j.rse.2010.04.025.

Elsherif, A., Gaulton, R., Mills, J., 2018. Estimation of vegetation water content at leaf and canopy level using dual-wavelength commercial terrestrial laser scanners. Interf. Focus 8, 20170041. https://doi.org/10.1098/rsfs.2017.0041.

Elsherif, A., Gaulton, R., Mills, J., 2019a. Four dimensional mapping of vegetation moisture content using dual-wavelength terrestrial laser scanning. Remote Sens. 11, 2311. https://doi.org/10.3390/rs11192311.

Elsherif, A., Gaulton, R., Shenkin, A., Malhi, Y., Mills, J., 2019b. Three dimensional mapping of forest canopy equivalent water thickness using dual-wavelength terrestrial laser scanning. Agric. For. Meteorol. 276-277, 107627. https://doi.org/ 10.1016/j.agrformet.2019.107627.

Feret, J.B., le Maire, G., Jay, S., Berveiller, D., Bendoula, R., Hmimina, G., Cheraiet, A. Oliveira, J.C., Ponzoni, F.J., Solanki, T., de Boissieu, F., Chave, J., Nouvellon, Y., Porcar-Castell, A., Proisy, C., Soudani, K., Gastellu-Etchegorry, J.P., LefevreFonollosa, M.J., 2019. Estimating leaf mass per area and equivalent water thickness based on leaf optical properties: potential and limitations of physical modeling and machine learning. Remote Sens. Environ. 231, 110959. https://doi.org/10.1016/j. rse.2018.11.002.

Gaulton, R., Danson, F.M., Ramirez, F.A., Gunawan, O., 2013. The potential of dualwavelength laser scanning for estimating vegetation moisture content. Remote Sens. Environ. 132, 32-39. https://doi.org/10.1016/j.rse.2013.01.001.

Guo, J.S., Hultine, K.R., Koch, G.W., Kropp, H., Ogle, K., 2020. Temporal shifts in iso/ anisohydry revealed from daily observations of plant water potential in a dominant desert shrub. New Phytol. 225, 713-726. https://doi.org/10.1111/nph.16196.

Hanusz, Z., Tarasińska, J., 2015. Normalization of the Kolmogorov-Smirnov and Shapiro-Wilk tests of normality. Biomet. Lett. https://doi.org/10.1515/bile-20150008.

Hellkvist, J., Richards, G.P., Jarvis, P.G., 1974. Vertical gradients of water potential and tissue water relations in Sitka spruce trees measured with the pressure chamber. J. Appl. Ecol. https://doi.org/10.2307/2402215.

Juneau, K.J., Tarasoff, C.S., 2012. Leaf area and water content changes after permanent and temporary storage. PLoS One 7, e42604. https://doi.org/10.1371/journal. pone.0042604.

Junttila, S., Vastaranta, M., Liang, X., Kaartinen, H., Kukko, A., Kaasalainen, S., Holopainen, M., Hyyppä, H., Hyyppä, J., 2016. Measuring leaf water content with dual-wavelength intensity data from terrestrial laser scanners. Remote Sens. https:// doi.org/10.3390/rs9010008.

Junttila, S., Sugano, J., Vastaranta, M., Linnakoski, R., Kaartinen, H., Kukko, A., Holopainen, M., Hyyppä, H., Hyyppä, J., 2018. Can leaf water content be estimated using multispectral terrestrial laser scanning? A case study with Norway spruce seedlings. Front. Plant Sci. 9, 299. https://doi.org/10.3389/fpls.2018.00299.

Junttila, S., Holopainen, M., Vastaranta, M., Lyytikäinen-Saarenmaa, P., Kaartinen, H., Hyyppä, J., Hyyppä, H., 2019. The potential of dual-wavelength terrestrial lidar in early detection of Ips typographus (L.) infestation - leaf water content as a proxy. Remote Sens. Environ. 231, 111264. https://doi.org/10.1016/j.rse.2019.111264.

Kaasalainen, S., Hyyppa, H., Kukko, A., Litkey, P., Ahokas, E., Hyyppa, J., Lehner, H., Jaakkola, A., Suomalainen, J., Akujarvi, A., Kaasalainen, M., Pyysalo, U., 2009. Radiometric calibration of LIDAR intensity with commercially available reference targets. IEEE Trans. Geosci. Remote Sens. https://doi.org/10.1109/ tgrs.2008.2003351.

Kaasalainen, S., Jaakkola, A., Kaasalainen, M., Krooks, A., Kukko, A., 2011. Analysis of incidence angle and distance effects on terrestrial laser scanner intensity: search for correction methods. Remote Sens. https://doi.org/10.3390/rs3102207.

Kankare, V., Räty, M., Yu, X., Holopainen, M., Vastaranta, M., Kantola, T., Hyyppä, J., Hyyppä, H., Alho, P., Viitala, R., 2013. Single tree biomass modelling using airborne laser scanning. ISPRS J. Photogramm. Remote Sens. https://doi.org/10.1016/j. isprsjprs.2013.08.008.

Klepper, B., 1968. Diurnal pattern of water potential in woody plants. Plant Physiol. 43, 1931-1934. https://doi.org/10.1104/pp.43.12.1931.

Konings, A.G., Rao, K., Steele-Dunne, S.C., 2019. Macro to micro: microwave remote sensing of plant water content for physiology and ecology. New Phytol. 223, 1166-1172. https://doi.org/10.1111/nph.15808.
Korpela, I., 2017. Acquisition and evaluation of radiometrically comparable multifootprint airborne LiDAR data for forest remote sensing. Remote Sens. Environ. https://doi.org/10.1016/j.rse.2016.10.052.

Krooks, A., Kaasalainen, S., Kankare, V., Joensuu, M., Raumonen, P., Kaasalainen, M., 2014. Tree structure vs. height from terrestrial laser scanning and quantitative structure models. Silva Fennica. https://doi.org/10.14214/sf.1125.

Kubiske, M.E., Abrams, M.D., 1991. Seasonal, diurnal and rehydration-induced variation of pressure-volume relationships in Pseudotsuga menziesii. Physiol. Plant. https:// doi.org/10.1034/j.1399-3054.1991.830116.x.

Liang, X., Kankare, V., Yu, X., Hyyppa, J., Holopainen, M., 2014. Automated stem curve measurement using terrestrial laser scanning. IEEE Trans. Geosci. Remote Sens. https://doi.org/10.1109/tgrs.2013.2253783.

Lintunen, A., Paljakka, T., Salmon, Y., Dewar, R., Riikonen, A., Hölttä, T., 2020. The influence of soil temperature and water content on belowground hydraulic conductance and leaf gas exchange in mature trees of three boreal species. Plant Cell Environ. 43, 532-547. https://doi.org/10.1111/pce.13709.

Martinez-Vilalta, J., Anderegg, W.R.L., Sapes, G., Sala, A., 2019. Greater focus on water pools may improve our ability to understand and anticipate drought-induced mortality in plants. New Phytol. 223, 22-32. https://doi.org/10.1111/nph.15644.

McDowell, N.G., Allen, C.D., 2015. Darcy's law predicts widespread forest mortality under climate warming. Nat. Clim. Chang. https://doi.org/10.1038/nclimate2641.

Nevalainen, O., Hakala, T., Suomalainen, J., Mäkipää, R., Peltoniemi, M., Krooks, A., Kaasalainen, S., 2014. Fast and nondestructive method for leaf level chlorophyll estimation using hyperspectral LiDAR. Agric. For. Meteorol. https://doi.org/ 10.1016/j.agrformet.2014.08.018.

Nichol, J., Hang, L.K., Sing, W.M., 2006. Empirical correction of low Sun angle images in steeply sloping terrain: a slope-matching technique. Int. J. Remote Sens. https://doi. org/10.1080/02781070500293414.

Nobel, P.S., 1999. Physicochemical \& Environmental Plant Physiology. Academic Press.

Olsson, K.A., Milthorpe, F.L., 1983. Diurnal and spatial variation in leaf water potential and leaf conductance of irrigated peach trees. Funct. Plant Biol. https://doi.org/ 10.1071/pp9830291.

Penuelas, J., Pinol, J., Ogaya, R., Filella, I., 1997. Estimation of plant water concentration by the reflectance Water Index WI (R900/R970). Int. J. Remote Sens. https://doi.org/10.1080/014311697217396.

Poorter, H., Niinemets, Ü., Poorter, L., Wright, I.J., Villar, R., 2009. Causes and consequences of variation in leaf mass per area (LMA): a meta-analysis. New Phytol. https://doi.org/10.1111/j.1469-8137.2009.02830.x.

Puttonen, E., Briese, C., Mandlburger, G., Wieser, M., Pfennigbauer, M., Zlinszky, A., Pfeifer, N., 2016. Quantification of overnight movement of birch (Betula pendula) branches and foliage with short interval terrestrial laser scanning. Front. Plant Sci. 7, 222. https://doi.org/10.3389/fpls.2016.00222.

Pyörälä, J., Kankare, V., Vastaranta, M., Rikala, J., Holopainen, M., Sipi, M., Hyyppä, J., Uusitalo, J., 2018. Comparison of terrestrial laser scanning and X-ray scanning in measuring Scots pine (Pinus sylvestris L.) branch structure. Scand. J. Forest Res. https://doi.org/10.1080/02827581.2017.1355409.

R. Core Team, 2015. An Introduction to R. Samurai Media Limited.

Rallo, G., Minacapilli, M., Ciraolo, G., Provenzano, G., 2014. Detecting crop water status in mature olive groves using vegetation spectral measurements. Biosyst. Eng. 128, 52-68. https://doi.org/10.1016/j.biosystemseng.2014.08.012.

Santos, A.O., Kaye, O., 2009. Grapevine leaf water potential based upon near infrared spectroscopy. Sci. Agric. https://doi.org/10.1590/s0103-90162009000300001.

Savage, M.J., Wiebe, H.H., Cass, A., 1983. In situ field measurement of leaf water potential using thermocouple psychrometers. Plant Physiol. 73, 609-613. https:// doi.org/10.1104/pp.73.3.609.

Scholander, P.F., Bradstreet, E.D., Hemmingsen, E.A., Hammel, H.T., 1965. Sap pressure in vascular plants: negative hydrostatic pressure can be measured in plants. Science 148, 339-346. https://doi.org/10.1126/science.148.3668.339.

Seddon, A.W., Macias-Fauria, M., Long, P.R., Benz, D., Willis, K.J., 2016. Sensitivity of global terrestrial ecosystems to climate variability. Nature 531(7593), 229-232. https://doi.org/10.1145/3308561.3353779.

Sevanto, S., Vesala, T., Peramaki, M., Nikinmaa, E., 2002. Time lags for xylem and stem diameter variations in a Scots pine tree. Plant Cell Environ. https://doi.org/ 10.1046/j.1365-3040.2002.00884.x.

Elson, E.L., 2001. A mathematical theory of communication. ACM SIGMOBILE mobile computing and communications review 5(1), 3-55. https://doi.org/10.1145/ 3308561.3353779 .

Syvertsen, J.P., Levy, Y., 1982. Diurnal changes in citrus leaf thickness, leaf water potential and leaf to air temperature difference. J. Exp. Botany. https://doi.org/ 10.1093/jxb/33.4.783.

Trenberth, K.E., 2011. Changes in precipitation with climate change. Clim. Res. https:// doi.org/10.3354/cr00953.

Wagner, W., Ullrich, A., Ducic, V., Melzer, T., Studnicka, N., 2006. Gaussian decomposition and calibration of a novel small-footprint full-waveform digitising airborne laser scanner. ISPRS J. Photogramm. Remote Sens. https://doi.org/ 10.1016/j.isprsjprs.2005.12.001.

Wheeler, T., von Braun, J., 2013. Climate change impacts on global food security. Science. https://doi.org/10.1126/science.1239402.

Yrttimaa, T., Saarinen, N., Luoma, V., Tanhuanpää, T., Kankare, V., Liang, X., Hyyppä, J., Holopainen, M., Vastaranta, M., 2019. Detecting and characterizing downed dead wood using terrestrial laser scanning. ISPRS J. Photogrammet. Remote Sens. 151, 76-90. https://doi.org/10.31219/osf.io/t2h8r. 